\title{
Mostly praise for 2018 federal budget from science and health care communities
}

\author{
C Cite as: CMAJ 2018 March 19;190:E343-4. doi: 10.1503/cmaj.109-5580
}

Posted on cmajnews.com on Feb. 28, 2018.

\begin{abstract}
t's safe to say that this year's federal budget may be the most popular in recent years among scientists, researchers and the medical community. Many areas of health and science that have been lacking in funding, such as fundamental research and Indigenous health, received welcome boosts. Money was also earmarked for fighting the ongoing opioid crisis. And national pharmacare made a buzz-worthy debut, though details remain vague. (Read CMAJ's previous article on the budget for a detailed breakdown of the funding for science and health.)
\end{abstract}

\section{Research}

Art McDonald, a member of Canada's Fundamental Science Review, was pleased to see the federal government adopt many of the recommendations made by the panel in its final report. The new money for research-granting agencies and stabilizing the Canada Foundation for Innovation will "be of benefit in stimulating the next generation of researchers to become involved," he said.

"The emphasis on science, innovation and diversity in the budget will create many benefits for Canadians in the future," added McDonald, a professor emeritus in the department of physics, engineering physics and astronomy at Queen's University.

Another member of the fundamental science review panel, Anne Wilson, said she was "pleasantly surprised" by the budget. The commitment to funding research - "unfettered, fundamental research" in particular - marks a mean-

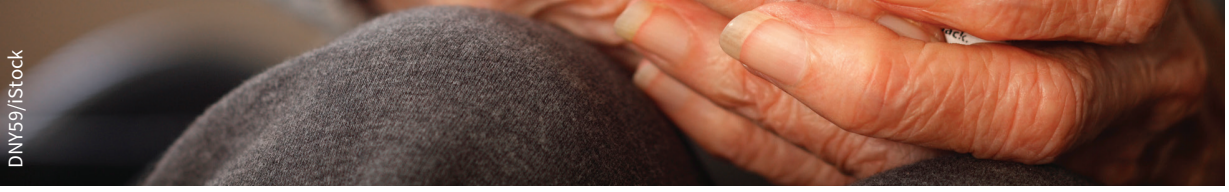

Some advocates for universal coverage of prescription medications are cautiously optimistic after the budget mentioned the creation of an advisory panel on implementing pharmacare. ingful change in trajectory for Canada, noted Wilson. The budget also provides a welcome boost to the country's research ecosystem, makes it easier for earlycareer researchers to obtain funding, and invests in high-risk research.

"In the past, these initiatives often fell through the cracks in a system not quite nimble enough to manage those needs," said Wilson, a psychology professor at Wilfred Laurier University and a Canada Research Chair in social psychology. "This update is welcome and important."

The budget was also a "brave move," suggested Wilson, because it showed that the government actually listened to Canada's scientific community, who had lamented the previous administration's neglect of basic science in favour of applied research with more economic potential. "Political actors can often gain more short-term points by supporting targeted funding that makes for a good headline," said Wilson. "Supporting fundamental research shows a longer-term vision and recognition that strengthening the foundations of unfettered, discoverybased inquiry yields meaningful returns to Canadian society over the long term."

According to Dr. Michael Schull, President and CEO of the Institute for Clinical Evaluative Science, the federal government's investment in evidence-based innovation and research will lead to more population-based, data-intensive, health studies. The resulting data will help guide the decisions of policy-makers across the country.

The opportunity to expand the data that is the foundation of our research is growing exponentially as biomedical data and social sector data become more available," said Schull. "Investments like these 
are crucial, allowing Canada's top researchers and decision-makers to access the data, computing power and expertise to fulfill the potential of data science to improve the health of Canadians."

\section{Pharmacare}

There has been much discussion about national pharmacare in Canada over the past few years, but little action. Will the budget's announcement of an advisory panel on the implementation of pharmacare be a step toward turning talk into reality?

"I'm cautiously optimistic," said Steve Morgan, a professor in the school of population and public health at the University of British Columbia, who has studied pharmacare extensively.

Morgan noted that the word "implementation" is literally in the panel's name. "I'm going to hold the government to that. This isn't a brand new 'dialogue' or study about whether national pharmacare is a good idea - that's been answered time and time again," he said. "I'll keep encouraging Canadians to put pressure on the government to see this stage of Canadian medicare across the finish line."

The initial excitement about the government's intentions for pharmacare, however, were "dispelled within 24 hours of the budget announcement," according to Dr. Monika Dutt, the executive director of Upstream, an independent nonprofit that focuses on addressing the social determinants of health to build a healthier society. Finance Minister Bill Morneau provided further details on the issue, and it appears the government plans to "stitch the gaps" in coverage while keeping the "inefficient and costly patchwork" of public and private coverage for drugs, said Dutt. "Single-payer coverage of prescription medications has long been seen as a major gap in medicare, and it will continue to be one."

\section{Indigenous health}

A recent series of articles in The Lancet urged Canada to make progress on addressing the health inequities experienced by Indigenous communities. According to one contributing author to that series, Margo Greenwood, the budget's promise of more funding to improve Indigenous health is good news.

"It is encouraging to see new investments, on top of the existing funds allocated in 2016, for Indigenous child welfare services in Canada," said Greenwood, the academic lead for the National Collaborating Centre for Aboriginal Health at the University of Northern British Columbia. "New spending to address underlying determinants of First Nations, Inuit and Metis health, such as housing and access to clean drinking water, are also a positive step for closing the health gaps."

Another member of Canada's Fundamental Science Review, Claudia Malacrida, also praised the budget's focus on indigen- ous health and health inequality. It presents a new way forward for important and necessary work to be done, said Malacrida, associate vice-president of research at the University of Lethbridge.

"This will require a shift in thinking towards regional and local strengths, community engagement, qualitative and Indigenous methodologies, and a focus for [the Canadian Institutes of Health Research] will need to include multidisciplinary teams and truly human-centred knowledge construction."

\section{The opioid crisis}

Few public health problems have dominated headlines in Canada more than the ongoing opioid crisis. The money promised to provinces and territories in the budget to help address the crisis is "certainly an acknowledgement of the problem," said Dr. Mark Tyndall, executive director of the British Columbia Centre for Disease Control. To make a real difference, however, that investment will need to fund work that looks at many factors, including housing, poverty, family supports, generational trauma and the prison system.

"It should be recognized that the social and economic drivers of the overdose epidemic cannot be solved through simply throwing more money at treatment and prohibition," said Tyndall.

\section{Roger Collier, CMAJ}

